\title{
UN PRATEIRO COMPOSTELÁN E O SEU ENTORNO FAMILIAR Tradición testamentaria de Rodrigo de Pardiñas
}

\author{
CÉSAR GÓMEZ BUXÁN
}

\begin{abstract}
Resumo
A cidade de Santiago de Compostela foi, durante moitos séculos, e en virtude da súa condición de arquidiocese e lugar de peregrinación, un centro de referencia para as artes suntuarias e relixiosas, entre as que destaca, de xeito moi especial, a pratería, que da nome, precisamente, a unha das máis coñecidas prazas da urbe. O obxecto deste artigo e realizar un superficial achegamento á peripecia vital dun prateiro compostelán, Rodrigo de Pardiñas, a través dos testamentos que outorgou ó longo da súa vida, así como dos documentos de últimas vontades de dúas das súas mulleres.
\end{abstract}

\section{Verbas clave}

Compostela, pratería, testamentos, xenealoxía.

\begin{abstract}
The city of Santiago de Compostela was, for many centuries, an by virtue of his condition of archdiocese and place of peregrination, a center of reference for the religious arts, and very especial way, the silverwork, which gives name, precisely, to one of de most known squares of the city. The object of this article is to realize a shallow approximation to the vital incident of a silversmith, Rodrigo de Pardiñas, across the testaments that he granted along his life, as well as of the documents of last wills of two os his wives.
\end{abstract}

\section{Keywords}

Compostela, silverwork, testaments, genealogy. 
A condición, innegable, da urbe Compostelá como fin e remate do camiño e, porque non e en certo xeito, desexo de multitude de peregrinos que desde o "descubrimento" do corpo do apóstolo Santiago ${ }^{1}$ ata hoxe percorreron os seus segredos, contribuíu a que a cidade se convertese nun centro, tanto relixioso como artístico, destacando unha arte de tipo suntuario, como a xoiería (ourivería, pratería e acibechería) que transformou as materias primas en cálices, relicarios, cruces procesionais, exvotos e moitos outros testemuños que aínda se conservan en boa parte $^{2}$.

$\mathrm{O}$ obxecto deste artigo é tentar un achegamento á figura dun dos prateiros composteláns, que exerceu o seu oficio durante a segunda metade do século XVI, Rodrigo de Pardiñas ${ }^{3}$, a través de varios testamentos outorgados por el e dúas das súas mulleres, a través de catro décadas, co que podemos coñecer parte da súa peripecia vital e familiar, así como algunhas obras da súa autoría das que non se coñecía a existencia.

\section{VIDA.}

A primeira referencia que temos de Rodrigo de Pardiñas o sitúa como oficial do prateiro Rodrigo Fernández, no $1545^{4}$, o que sitúa o seu nacemento posiblemente na década do 1530 .

A súa orixe, ignorada, aínda que os seus devanceiros debían ser dalgunha familia con recursos, como testemuña o cargo de racioneiro ocupado polo seu irmán, ou os seus enlaces matrimoniais.

En 12 de maio de 1570 o concello de Compostela lle fixo nomeamento de "marcador de la plata y oro" da dita cidade 5 . O seu obradoiro estaba na primeira das sete

\footnotetext{
${ }^{1}$ Sexa real ou non, o que non se pode negar é a relevancia do Camiño como difusor da cultura ó longo de toda a Idade Media e aínda hoxe, situándose por riba de supostas realidades ou invencións o seu trasfondo relixioso, cultural e poboacional.

${ }^{2}$ Para calquer investigación sobre as manifestacións artísticas na Galiza dos séculos XVI e XVII é de referencia a obra de Pérez Constanti, e para a que abrangue os séculos XVIII e parte do XIX, a de Couselo Bouzas. As edicións consultadas son as seguintes: PÉREZ CONSTANTI, Pablo: Diccionario de artistas que florecieron en Galicia durante los siglos XVI y XVII. Ed. facs. Santiago de Compostela, Consellería da Presidencia e Administración Pública, Servicio Central de Publicacións, 1988. COUSELO BOUZAS, José: Galicia artística en el siglo XVIII y primer tercio del XIX. Santiago de Compostela, Instituto de Estudios Gallegos "Padre Sarmiento", 2004.

${ }^{3}$ Tamén figura como Paradinas, sobre todo nos últimos anos da súa vida.

${ }^{4}$ COSTANTI, 420.

${ }^{5}$ Cargo vacante por defunción do prateiro Pedro Varela, sogro de Rodrigo de Pardiñas. COSTANTI, 418 .
} 
tendas das Praterías, pola que pagaba de renda anual ó Cabido oito ducados e un par de capóns cebados ${ }^{6}$.

Durante a súa vida mercou cantidade de bens, como una casa e lugar en Ribadulla, un lagar coa súa adega e torre en Santo Adrao de Bieite ${ }^{7}$, ou unha casa na entrada da Rúa Nova, en Santiago. Así mesmo semella que posuía un oficio de Receptor de Primeiro Número da Real Audiencia, que procedía de Pedro Farina.

En todo caso, mentres no testamento que outorgou no 1565 (Colección documental, $\mathrm{n}^{\circ} .1$ ) e o da súa muller María López do 1569 (Ídem, $\mathrm{n}^{\circ} .2$ ), figura o seu oficio como o de prateiro, nos seguintes documentos non se indica a súa ocupación, o que nos leva a pensar que trocara a súa ocupación principal pola de comerciante.

Morreu o 6 de febreiro do 1609, día no que se efectúa a apertura do seu derradeiro testamento, cando Rodrigo de Pardiñas "está amortaxado y para sepultar" e "se tanen por el las canpanas".

A súa sepultura, segundo ordena en tódolos documentos que outorgou, se debería efectuar na capela de San Bieito do Campo da cidade de Santiago de Compostela, nun enterramento que fixo no seu interior entre o 1594 e o 1605 , coa súa terceira muller "en el altar coliteral a la parte ysquierda en el lado del ebanxelio", segundo declara no seu derradeiro testamento de 29 de xaneiro de 1609.

\section{A FAMILIA.}

Dos seus devanceiros, como xa dixemos, nada cita nas súas últimas vontades. No referido ós seus parentes consanguíneos, sabemos do Racioneiro Juan de Paradinas, o seu irmán, vivo aínda cando morreu Rodrigo, e do sobriño deste último, Francisco de Pardinas.

Casara Rodrigo de Pardiñas en tres ocasións. De primeiras nupcias con María López, que outorgou testamento o 10 de novembro do 1569 ante Gonzalo de Reguera (Colección Documental, $\mathrm{n}^{\circ}$. 2), mandando ser soterrada na capela de San Bieito do Campo "en la sepultura que allí tengo entre los demás questán en la dicha capi1la". Así mesmo manda doce ducados para axuda da obra do coro da dita capela do Campo "que se quiere hazer i hedeficar". Deste matrimonio quedaron catro fillos:

1). María. Sen sucesión.

2). Juan. Sen sucesión.

\footnotetext{
${ }^{6}$ COSTANTI, 419-420.

${ }^{7}$ Concello de Leiro - Ourense.
} 
3). Francisco. Sen sucesión.

4). Rodrigo de Pardiñas. Vivía aínda no 1594, pero moi enfermo.

De segundas nupcias enlazou con María Fernández, filla do prateiro Pedro Vare$l^{8}{ }^{8}$ e da súa muller, outra María Fernández, irmá do tamén prateiro Pedro Varela ${ }^{9}$, e dela tivo a:

5). Pedro de Pardinas. Crego e rector de Santo Andrés de Illobre.

6). Filla, que faleceu sen descendencia no 1593.

Finalmente, a súa terceira muller foi Catalina Oanes de Salamanca, coa que lle foron dotados cincocentos ducados polos que tivo preito Rodrigo de Pardiñas con Ana de Ortega. Catalina Oanes fixo testamento o 9 de novembro de 1605 (Colección documental, $\mathrm{n}^{\circ}$. 5) ante Pedro Díaz de Valdivieso, no que ordena ser sepultada na antedita igrexa de San Bieito do Campo "en la capilla que allí hicimos yo y mi marido". Deles naceron:

7). Diego de Pardinas (ou Farina). Procurador na Audiencia Arcebispal de Santiago, cidade de onde era veciño.

8). Frai Francisco de Barrientos (ou de Pardinas). Monxe en Celanova.

9). Catalina Oanes. Solteira no 1605 e mellorada pola súa nai no tercio e quinto dos seus bens. Tamén foi mellorada no tercio e quinto polo seu pai no testamento co que morreu.

10). Juan de Pardinas.

11). Alonso Farina.

\section{OBRA.}

Nos testamentos que se achegan, ademais dos datos familiares, tamén se poden sacar interesantes noticias das obras que fixera ou que estaba a facer no seu taller o devandito Rodrigo Pardiñas, así como o nome de varios prateiros de Compostela, informacións que non ofrecemos separadamente por saír fóra da temática do presente artigo.

\footnotetext{
${ }^{8}$ Figura referencia sobre este prateiro en COSTANTI, 538-539.

9 Íbidem.
} 


\section{COLECCIÓN DOCUMENTAL}

Na edición dos textos se seguen os criterios comunmente adoptados na actualidade para estes efectos, xa coñecidos.

156[5], agosto, 18. Cidade de Santiago

Testamento de Rodrigo de Pardiñas, prateiro, veciño da cidade de Santiago. AHUS, Protocolos, S-357, 104-106.

In dei nomine amen sepan quantos esta carta de manda e testamento vieren como yo Rodrigo de Pardiñas platero, vecino de la çibdad de Santiago, estando enfermo en cama y en mi seso y juizio natural ago y hordeno mi manda e testamento en la manera y forma seguiente.

Primeramente mando mi ánima a nuestro senor Jesucristo, quien conpró e redemió por su preçiosa sangre en el árbol de la vera cruz e ruego [e suplico] por merced a la gloriosa birgen maria quiera rogar a su hijo bendito me perdone mis pecados para que pueda gozar de su santa gloria Amen.

Yten mando que quando Dios nuestro senor fuere servido de me llebar desta presente vida que mi cuerpo sea sepultado en la capilla de San Benito de la dicha çibdad.

Yten mando al clérigo que me tubiere por la mano al tienpo de mi falesçimiento quatro reales.

Yten mando a la Santa Cruzada e redençión de cautibos diez maravedís e con esto lo aparto de mis vienes.

Yten mando quel día de mi entierro y honrras digan por mi ánima quarenta misas las treinta rezadas y las diez cantadas a donde paresçiere a mis conplidores.

Yten mando a la capilla de San Fyns donde soy feligrés una carterola de açeite y otra a la capilla de San Benito por razón de la sepultura que se me tiene de dar.

Yten mando que repartan entre pobres bergonçosos çincoenta reales por que rueguen a Dios por mi ánima lo qual se les de lo más brebe que ser pueda después de mi falesçimiento.

Yten digo que reçibi de la senora dona Mayor de [Baldes] çiertos marcos de plata para azer una cruz la qual tengo hecha mando que se acabe a mi costa e se pague lo que he de aber conforme al contrato que pasó por delante Juan Valeira escrivano y la plata que tengo resçibida costará por mi libro y conosímientos que di a la dicha senora dona Mayor a lo qual me refiero y en ello ruego y encargo a mi conplidor trate que de una parte para otra no aya engano. 
Yten digo que Francisco de Saa, vezino desta çiudad y un clérigo de Santa María de Saar me entregaron el pie de una cruz para que yo la adereszase digo que tengo en mi poder todas las pieças del pie de la dicha cruz mando que se le entreguen con mas un caliz que ansimesmo tengo del dicho monesterio de Saar.

Yten digo que tengo en mi poder un caliz de plata dorado ques de la confradía de los plateros de la dicha çibdad mando que se la entreguen a la dicha confradía con que se me pague y a mis herederos çincoenta reales en que les alcançe en la cuenta que entre nos hizo Pedro Barela y Juan Rodríguez frade y [Ubaldin Bonete] y de los dichos çincoenta reales quito diez para serviçio de la dicha confradía y ansimesmo le ago graçia e quita de otra qualquiera cosa que me deba y sea obligado a pagar la dicha confradía y no abiendo la dicha confradía y del aziendose no le mando ninguna cosa y mando se cobre realmente lo que se me debe porquesta hes mi entenzión e voluntad e no de otra manera.

Yten me debe el raçionero Juan de Paradinas, mi hermano, treinta e un ducados menos un real que pague por el por los frutos del benefiçio de Santa María de Leiloyo ${ }^{10}$ mando se cobren del y le suplico los pague a María López, mi muger y ansimesmo declaro me debe por otra parte çiento y tantos reales según paresçerá firmado de su nonbre e mi [libro].

Yten más declaro que me debe por otra parte çiento y çincoenta e tantos reales que por el como su fiador de abono pagué a Pedro da Fonsin y a Jácome Fernández alabardero, la qual dicha deuda debía el dicho raçionero mi hermano como fiador de Diego Xuares de Narabal y esta la paga destos maravedís a cargo del dicho Diego Xuares de Naravales, suplico y pido por merced al dicho raçionero Juan de Pardiñas que aga cobrar y cobre estos maravedís del dicho Diego Xuares porque por su causa y a su ynstança los pague.

Yten digo que yo traté pleito delante Juan Romero merino de Folgoso con unos honbres que alçaron una bolsa con doze ducados que abía perdido un mi criado y están sentençiados a que me los buelban mando que se acabe de fenesçer y se cobren los dichos maravedís.

Yten digo que a mi me deben muchas personas quantías de maravedís y las personas y quantías que son constará por obligaçiones y por mi libro digo que lo questa escrito y tildado en el dicho libro y las dichas obligaçiones ansí de lo que debo como de lo que me deben todo hello digo es çierto y verdadero y pasa en realidad de [verdad] como en el se contiene y conforme a hello quero y es mi boluntad se cobre y pague y se pase por ello en todo y por todo como en el se contiene.

${ }^{10}$ Santa María de Leiloio, en Malpica de Bergantiños (A Coruña). 
Yten digo que tengo en mi poder dos cáliz, el uno del venefiçio de San Lorenço de [Bruna] y el otro de un honbre que no se donde hes natural y el dicho cáliz lo traxo el dicho honbre de poder [de Martín Fernández] e me lo entrego para que se lo aderezase [Martín Fernández] dirá donde hes el dicho honbre.

Yten dexo por cunplidores y esecutores deste mi testamento a María López mi muger y a Marcos Fernández y a Juan das Seijas platero y a Lope Díaz de Páramo, mercader, y a cada uno dellos ynsolidun y les doy poder conplido para que [entren mis] vienes y de su balor cunplan este mi testamento como en el se contiene y lo más que les paresçiere sea y debe de azer para descargo de mi ánima y conçiençia.

[E] conplido e pagado este mi testamento en lo más remaneçiente de mis vienes dexo por mis herederos a Juan y a María de Pardiñas, mis hijos legítimos e de la dicha mi muger y al hijo o hija de que la dicha mi muger está preñada para que los lleben y gozen por yguales partes con la mi bendizión y con la de Dios y muriéndose cada uno de los dichos mis hijos sea el otro su heredero y ansi se entienda asta el postrero dellos y por quanto son menores los dichos Juan y María les dexo por tutor y curadora y admenystradora de sus personas y vienes y a la dicha su madre y casandose la dicha mi muger, ruego y pido por merced a Juan das Seijas y a Marcos Fernández platero sean curadores y admenistradores de las personas e vienes de los dichos mis hijos porque Dios dexe quien por sus cosas aya lo [mysmo] y reboco otros quales quiera testamentos y [cobdizillos] que antes deste aya hecho y otorgado ansi por escrito como por palabra para que no bala ni agan fee en juicio ni fuera del salbo este que al de presente ago y otorgo que quiero que bala como mi testamento última e postrimera boluntad por la bia que puede y debe baler y ansi lo otorgo por delante bos el presente escrivano e testigos que fue fecho y otorgado en la ciudad de Santiago a diez y ocho días del mes de agosto de mil e quinientos e sesenta e [çinco] años.

Yten mando que llamen las confradías de [nuestra] senora de la Conseçion y de San Tomé y San Giao y de los plateros porque soy confrade de todas las dichas confradías para que vengan a mi entierro y honrras.

Yten digo que yo tengo çierta cuenta con Fernando [da Pireira] el moço y esta sentado lo que hes y la claridad dello en mi libro de cuentas ruego y encargo a mis cunplidores lo sepan y fenescan y abriguen con el y se aga la cuenta por manera que de una parte ni otra no aya fraude ni engano.

Yten digo que agan cuenta con Gonçalo Domingues mi criado y se le pague lo que se le debiere a presçio de un ducado cada mes que le pagaba y demás dello le mando las mis calças negras de [carisea].

Yten mando a Francisco de Pardinas, mi sobrino, un sayo negro de mi persona y un capote color negro estando a todo hello presentes por testigos llamados e roga- 
dos Marcos Fernándes e Juan das Seijas e Fernando da Pereira, el Moço, plateros, y Álvaro da Silba, sastre e Pedro de Milmanda, veçinos e moradores en la dicha çibdad e yo escrivano doi fee que conozco al dicho otorgante y lo firmo de su nonbre. Rodrigo de Paradinas [sin.]. Pasó ante mi Gonçalo de Reguera, escribano [sin.]. No recibe derechos.

\section{2}

1569, novembro, 10. Cidade de Santiago.

Testamento de María López, muller de Rodrigo de Pardiñas, prateiro, veciña da Cidade de Santiago.

AHUS, Protocolos, S-362, ff. $342-345$.

Yn dei nomine amen sepan quantos esta carta de manda y testamento vieren como yo María López muger de Rodrigo de Pardinas platero bezino de la çiudad de Santiago estando mal despuesta con mi seso e juizio [natural] que dios nuestro senor fue serbido de me dar rreçelandome de la muerte que es cosa natural creyendo como creo en la Santa fe católica padre e hijo espritu santo tres personas e un solo Dios berdadero ago y ordeno mi manda e testamento en la manera seguiente por la qual encomiendo mi anima anima [sic] a mi senor chuxpo que la conpro rredemio por su preçiosa sangre e rruego e pido por merçed a la gloriosa virgen maria madre de mi senor chuxpo abogada de los pecadores rreina de los angeles quiera ser mi abogada e ynterçesora por mi anima a su hijo bendito en todos los mis fechos para que mi anima pueda entrar en su santa gloria e corte celestial con sus santos e santas bienabenturados amen.

Yten mando que quando nuestro senor fuere serbido de me llebar desta presente bida mi cuerpo sea sepultado en la capilla de San Benito del Canpo en la sepultura que allí tengo entre los demás questan en la dicha capilla e mando a la dicha capilla de San Benito doze ducados para ayuda de la obra e corregimiento del coro de la [dicha] capilla que se quiere hazer i hedeficar.

Yten mando al clérigo questobiere presente al tienpo de mi falesçimiento y encomendare mi ánima a Dios nuestro senor [quatro reales] estando presente el clérigo e rretor donde soy feligrés este prefiera [a otro] que se allare presente.

Yten mando que para mi entierro e honrras llamen las confradías de nuestra senora de la Concebçion y Santaloy de los plateros e de Santo Tomé e de San Giao de los herreros de quel dicho mi marido hes confrade e debiendo de se les pagar alguna limosna se pague. 
Yten mando que día de mi entierro e honrras diganse treinta misas por las ánimas de purgatorio todas ellas rrezadas digo que se digan los días que se podieren dezir e otras treinta por las animas de quien soy en alguna obligaçion e cargo e las diez dellas sean cantadas en las yglesias e monesterios que paresçiere a mis conplidores.

Yten mando a los pobres y enfermos de Santa Marta e San Lázaro a cada horden tres ducados con que agan dezir cada una de las dichas hordenes por mi anima [dos] misas rrezadas en sus capillas donde oyen misa y estén a las dichas misas los que podieren e rruegen a Dios por mi anima porque nuestro senor la lliebe a su Santa Gloria con sus santos bien abenturados amen.

Yten mando seis ducados para ayuda de los gastos de los pobres y huerfanos del [dicho] ospital Real e pido e suplico [a los] senores capellanes del dicho ospital sean serbidos de benir e allarse presentes a mi entierro e honrras por serbicio de Dios nuestro senor.

Yten mando que de la tela de [lienço] que tengo en casa de Gregorio [Bonxes] [e seda] que tiene beinte e dos baras de la dicha tela se haga una bestimenta conplida para el serbicio de la capilla de Baldomar y dar la dicha bestimenta echa e conpuesta a la dicha capilla porque nuestra senora ruege a nuestro senor por mi.

Yten digo que Bastián Martínez herrero e su muger me deben y son obligados a pagar siete reales e por buenas obras que dellos he rrecebido les ago graçia e quita dellos.

Yten digo que la muger de Juan Domingez [de Mendon] bezino desta çiudad me debe dos ducados e tres reales e medio que le presté mando que cobren los dos ducados e de los tres reales e medio le ago graçia e quita dellos por ser como hes pobre.

Yten digo que Pedro Gonçales herrero vezino desta ciudad me debe seis reales que le preste sobre un poco de azero mando que cobren los quatro reales e le ago quita de los dos.

Yten digo que Miguel [...] vezino desta [...] me deve quinze reales mando que cobren los doze dellos le ago graçia y quita de los tres.

Yten mando [Ana] de Chaves criada que fue de Juan López Ponbo capellán mayor del ospital rreal dos mantas de burel e mas una sábana porque ruege a Dios por mi anima.

Yten mando otra manta de burel a Ana Gómez de la qual dicha manta falta un pedaço.

Yten mando a Ynes Fernándes por los buenos serbicios que me a echo muger de Rodrigo de Portas una hanega de trigo que son seis ferrados lo qual se le entregue despues de mi falescimiento para ayuda de su remedio. 
Yten mando a la muger que finco de Baltasar Leal escrivano una saya negra que tengo para ayuda de su remedio.

Yten mando a María Fernández muger pobre una camisa e unas mangas coloradas e unos cuerpos berdes e quiero los lliebe e rruege a Dios por mi anima.

Yten mando a Luzia de Panaderos muger de Luis Álbarez tonelero la mi saya [...] que tengo.

Yten mando el my manto de [...] Adega Varela muger de Bartolomé Rodríguez [...] porque tenga por bien de rogar a Dios por mi ánima.

Yten mando que se pague a Ynés mi moça de serbiçio todo lo que le debo de su soldada e demás dello le mando una camisa e unos cuerpos azules con sus mangas.

Yten mando a mi hija María la mi saya de grana colorada guarnecida de terciopelo carmesí e si Dios nuestro senor fuere serbido de la llebar desta presente bida mando que la dicha ropa se de a nuestra señora de conjo para ayuda del serbicio della.

Y ansimesmo mando a la dicha mi hija tres anillos de oro e dos joyeles e unas almendrillas de oro e quiero los lliebe e goze demás que los otros mis hijos e si se falesciere se reparta entre los mas mys hijos y herederos.

Yten mando quel dia de my entierro den a los pobres que benieren a mi puerta la limosna que paresciere al dicho Rodrigo de Pardinas my marido.

Yten digo que tengo en mi arca ciertos maravedís que son de Alonso da Cancela presbítero [...] de dos toneles de bino e los maravedís que son esta escrito en un papel questa junto de los dichos maravedis mando se le paguen y entreguen.

Yten digo que María Fernández tiene a su cargo la venta de un tonel de bino que le entregue de porte de doze moyos e un canado e della tengo rrecebido beinte e quatro ducados con un manto e varias almendrillas que [en] todo ello monta los dichos beinte e quatro ducados mando que se le pida lo [más] que montare el dicho bino.

Yten dexo por conplidores y esecutores deste mi testamento e de las mandas e legatos en el contenidas al dicho rr $^{\circ}$ de Pardinas, e Fr ${ }^{\circ}$ de Pereira, platero, el moço vezinos de la dicha çiudad e a cada uno dellos ynsolidun e les doy poder conplido para que entren mis bienes e cunplan este mi testamento en el [hes].

Yten mando a la obra de senor San Roque [...] ducados por que sea mi abogado.

Yten mando a la Santa Cruzada e rredençion de catibos medio rreal e con esto le aparto de mis bienes.

Yten dexo por mis herederos a María [e Juan] e Françisco, e Rodrigo, mis hijos legítimos [e del] dicho mi marido para que ayan e leben e gozen y hereden los dichos mis vienes y [herençia] con la bendiçión de Dios e la mía [e...] cada uno 
dellos que [el otro] sea su heredero e moriendose todos los dichos my hijos antes de my falesçimiento y en tal caso quiero que los dichos mis bienes los aya llebe goze el dicho Rodrigo de Pardinas my marido e dellos y en ellos aga a su voluntad e tenga cuenta de hazer e cumplir lo que conbeniere a descargo de my anima e conciencia porque ansi lo quiero y es mi voluntad.

Yten digo que por este mi testamento dixo e mando a la dicha capilla de San Benito del Campo para ayuda de la obra del coro de la dicha capilla del Campo quiero y hes mi boluntad que si la dicha obra se hiziere se den los dichos doze ducados e no se haziendo quiero no se le den antes quiero que mis conplidores los gasten e destribuyan por mi ánima en limosnas e obras pías que a ellos les paresciere porque ansi hes mi boluntad.

Yten dexo fago e otorgo por mi manda e testamento última e postrimera voluntad e rreboco caso y anulo e doy por ningunos e de nengún balor y efecto otras quales quiera mandas e testamentos e code[çilios] que antes de aora aya echo e otorgo ansi por escrito como por palabra que quiero no balan ni hagan fee en juizio [...] aun [...] en ellos e qualquiera dellos se contengan [qualesquiera] clausolas derogatorias que quiero no balan salbo este por mi ultima e postrimera boluntad [que por] bia que de derecho mexor obiere lugar e ansi lo otorgo antel presente escrivano e testigos que fue fecho e otorgado en la çiudad de Santiago a diez días del mes de [noviembre] de mill e quinientos e sesenta e nuebe anos estando presentes por testigos Fernan de Pereira, platero, e Domingo Cavaleiro e Bastián [Martínez] herrero e $\mathbf{R}^{\mathbf{o}}$ Azedo platero vezinos de la dicha ciudad e Francisco Garçia bezino de la felegresía de San Lorenço de [Bruma], e yo escrivano doy fee conozco a la dicha otorgante e a su rruego lo firmo el dicho Domingos Cavaleiro de su nonbre en mi rregistro. Domingo Cabaleiro [sin.]. Pasó antemi Gonçalo de rreguera, escrivano [sin.]. Pagoseme dos reales.

1594, xuño, 28. Cidade de Santiago.

Testamento de Rodrigo de Pardiñas, veciño da cidade de Santiago.

AHUS, Protocolos, S-503, ff. 157 - 161.

Yn Domine amen Sepan quantos hesta carta de manda y testamento vieren como yo Rodrigo de Paredinas, vezino de la ciudad de Santiago hestando enfermo con mi seso y juizio natural hordeno mi testamiento por el qual creiendo como creo firmemente la Santa Fe católica Padre hijo spiritu santo tres personas y un solo Dios 
verdadero y mando mi anima a Dios nuestro senor que la conpro y redemio por su preçiosa sangre en la arbol de la Santa Cruz e Ruego y pido por merçed a la gloriosa virgen maría su bendita madre que con todos los santos y santas de la corte çelestial quiera ser mi abogada y supplicar a mi senor Jesuxpo me perdone mis culpas y pecados para que pueda entrar y gozar de su santa gloria amen.

Yten mando al clérigo que hestubiere presente al tienpo de mi falesçimyento y encomendare mi anima a Dios seis reales.

Yten mando que mi cuerpo seya sepultado en la capilla de San Benito entre los dos altares del medio devaxo donde hesta mi primera muger María López.

Yten mando que para mi entierro y honrras llamen las confradías de senor santo [Eleyo] de los plateros y senor San Tomé y la Bera Cruz y San Giau y Santisteban de que yo soy confrade y mando les paguen las caridades que paresçiere deber y lo más acostunbrado.

Yten suplico a la cofradía del rrosario sean serbidos de me enterrar atento que los he serbido más de treinta anos / y mando les den seis ducados para el gasto de la çera si fueren serbidos si no fueren serbidos por los seis ducados no se llamen.

Yten mando a la Santa Cruzada y rredençion de cautibos un rreal y con esto le aparto de mis vienes.

Yten mando a nuestra senora de la Çerca y al senor San Benito a cada una dellas una carterola de açeite y mando se le paguen la sepultura lo que dixeren mis complidores atento que para la obra della di doze ducados.

Yten mando quel día de mi entierro se digan dos misas en la capilla de las Animas por mi anima.

Yten mando quel día de mi entierro y onrras se digan cinquenta misas las diez cantadas y las mas rreçadas por mi anima y de mis mugeres a quien tengo obligaçion.

Yten mando se llamen para el día de mi entierro el capellán de San Benito con media docena de testigos // y ansimesmo mando se llame la Horden de San Francisco y por ellos le paguen lo ques de costunbre //.

Yten mando me entierren en el Abito de San Francisco y por ello se pague lo acostunbrado.

Yten mando quel día de mi entierro se de quatro ducados a quatro pobres bengonçosos por çierta obligaçion que tengo.

Yten mando quel ano y día de mi entierro se me diga beinte misas / las quatro cantadas y las demás rrecadas y llamen para el ano y día la cofradía de la bera cruz y de los plateros // y les pagen lo que en que se conçertaren.

Yten digo que yo devo duçientos y cinquenta ducados de la Renta de la Ulla mando que se paguen sobre quinientos rreales que yo mande a Rodrigo da Fonte 
que lo ha de tomar en quenta y otros veinte y quatro reales que me debe de resto del fuero de la Ulla del ano de mil e quinientos e nobenta y uno e nobenta e dos e me debe la renta del ano de nobenta e tres.

Yten digo que yo devo duçientos e tantos ducados de çenço al monesterio de Balbis de que pago quinze ducados y ansimesmo debo a Lorenço de Cortinela ciento y doze ducados a çenço de que le pago ocho ducados mando a mis cumplidores que dentro del ano e día se rredima heste çenço a costa de mis vienes // sin faltar cosa alguna.

Yten digo que yo debo a un criado del ynquisidor y el agora Racionero de Santis Peritus doze ducados de una sincura de Brandomes mando se le pague.

Yten digo que yo tengo Arrendado el arçideanazgo de Cornado que pague por el ante [...] treçientos y treinta ducados y para la paga dellos me prestó Fernando de Valmayor por duçientos ducados y le tengo de dar la mitad de la ganançia que se ganase en el mando el dicho Fernando de Balmayor bea las escrituras de arriendo questando delante Domingo Cavaleiro escrivano conforme a hellas baya cobrando sus duçientos ducados y la gançia (sic) que quedare se entere en la mitad della y asimesmo Luis de Paz mercader vezino desta çiudad me dio setenta y çinco ducados para pagar los otros çiento y treinta ducados y le tengo de dar el quarto de la ganançia de la dicha rrenta mando que de los partidos que tiene se pague de sus setenta y çinco ducados y de la ganançia que le cupiere la quarta parte y mas su gançia (sic).

Yten digo que desta misma Renta coxi dos partidos, el uno de Pilono y el otro de Bama de que tengo de dar quenta y el de Pilono lo tome que tengo de dar quenta y el de Pilono lo tome en beinte mill maravedís y el de Bama en beinte y çinco mill maravedís y los demás partidos hestan en el ofiçio del dicho Domingos Cavaleiro =

Yten digo que yo e Pedro [Mallo] vezino Dabelenda tenemos quantidad de yeguas quel las declarará e nuebe piezas de bacas y un memorial del dinero que le tengo dado para comprar mulas para entre anbos // y ansimesmo me tiene alla una meda de trigo de entranbos y dos de la renta de rrestante y çierto pan e mijo mando se cobre y se aga quenta con el.

Yten digo que yo tengo en San Payo de Sabugeira una meda de pan de trigo y mas toda la renta de los Votos de Vama que todo sabe Juan [Dortegueira] lo que hes ruego le que lo cobre y coxa y lo entregue a mis herederos y le paguen su trabaxo todo lo que mereçiere por la amistad que tenemos los dos.

Yten digo que yo tengo en casa de mi amo Juan Costal en el puesto Bendana una arca casi mediada de pan y çierto millo mando se le tome quenta del ques onbre que dira la berdad.

Yten digo que yo tengo en San Martiño de Dornelas çiertas yiegoas con Graviel Martín e quel dira las que son y tienen burro entre anbas // y Pedro Mallo tiene otro ques mío solo // 
Yten digo que yo tengo en Santo Adrao de Bieite en el Riverodabia treinta e dos cabaduras de Bina poco mas o menos y ocho cubas y un lagar poco más de la mitad de la Torre y una bodega Payo Pérez dirá todo lo que hes para que se cobre [todo] a cuenta del.

Yten digo que yo fui casado con María López mi primera muger y por muerte della me quedaron dos o tres hijos e hize requento de los vienes que quedaron questa en mi hescritorio con el testamento della y agora no tengo sino un hijo della que se llama Rodrigo de Pardinas y estava mui malo mando si hes bibo y beniere por la parte de la legitima de su madre le den todos los vienes que yo tengo en la feligresía de Santo Adrau de Bieite y en los mas [vienes] que se allaren libres míos entre a la partixa con los más Hermanos.

Yten digo que yo fui casado segunda vez con María [Fernández] mi segunda muger hijo de Pedro Barela y por muerte della me quedaron un yjo y una hija y el hijo que se llama Pedro de Pardinas hes bibo y la muchacha se murió el ano pasado mando que todos los vienes que se allare aver sido de la dicha su madre así muebles como rraizes se le den al dicho Pedro de Pardinas con que saque la parte que yo podía heredar por la muchacha y en lo demás entre a partixa con los demás hermanos y le encargo tenga quenta con ellos como mayor.

Yten digo que yo fui casado terçera vez con Catalina Oanes [de Salamanca] y con ella me dieron quinientos ducados en dote con çiento que aún debe Ana Dortega questa [ese] pleito pendiente en la Audiençia Real digo que los quisiere sacar los saque y en lo demás entre a partixa y parta con sus hijos y tenga quenta con ellos por serbiçio de Dios y le mando para su bebienda la casa en que vive Juan [Fernández] de Santiago por los días de su vida.

Yten digo que yo tengo la casa y lugar de Rivadulla que conpre con la huerta en que ella tiene la mitad digo que si Pedro de Pardinas fuere clérigo y se conchavare con ella con sus hermanos y la quisiere rreconpensandole pan de rrenta con ella por ello de sus vienes propios se la dexen si hella y su senora se conçertaren.

Yten digo que yo tengo çiertas hescrituras y bentas que tengo echas ansi deste lugar como de otros lugares y casas y eredades mando las partan hermanamente con la bendiçión de Dios y la mía // y mando a Pedro de Pardinas tenga quenta con su senora y con sus hermanos y no se parta della entretanto hella no se casa[re] // y despues que se casare lliebe consigo a Françisqui[ño] su hermano y le ensene de buena criança y de su hestudio.

Yten digo que a mi me deven muchas deudas asi por obligaçiones conosçimientos memorias de [livros] asi de un libro biexo como de otro nuevo y enboltoreos de Papeles digo que todo se me debe lo questubiere por vorrar y si alguna per- 
sona dixere que me tubiere pago alguna partida desta conque sea pequena tomandosele su juramento se le tomen quenta.

Yten digo que yo tengo resçividos treinta e dos ducados para una cruz para la feligresía de Vama mando que trayendo el mas dinero [Bartolomé] de Ponte la acabe y se la de.

Yten digo que yo tengo rresçevido beinte y quatro ducados Para una cruz que avia de hazer para San Salbador Desquadro y agora quieranla haçer para Sa Mamed de Moalde digo que mis herederos trayendo lo mas rrestante la den acavar al [Bartolomé] de Ponte.

Yten digo que yo tego un moço que me sirve ará un año para la quaresma mando que acabe de serbir los tres anos a su $\left[\mathrm{ss}^{\mathrm{a}}\right]$ y le pagen todos tres anos todo lo que mereçiere y no se le desquente rropa ni otra cossa que yo le aya dado y le mando mas dos ducados y con lo que yo le debiere de los tres anos aprenda un [ofiçio] quel quisiere.

Yten digo que yo tengo una moça y una moça que su $\mathrm{ss}^{\mathrm{a}}$ sabe lo que ha serbido mando se les pague que la quenta dellas hesta en un libro biexo en el caxon questan los papeles de rribadabia y en ello hestan todas las hedades de mis hijos // mando se les pague todo lo que se le debiere.

Yten dexo por mis cumplidores y testamentarios al raçionero Juan de Pardinas mi hermano y a Luis de Paz [mercader] y a Francisco de Calçada secretario del Santo Ofiçio y a cada uno dellos ynsolidun para que puedan entrar en mis vienes asta cunplir mi testamento hes[tenço] lo puedan rredemir aunque sea pasado el ano y día // y cumplido e pagado heste mi testamento dexo (tach.) por mis conplidores (tach.) por mis herederos a Rodrigo de Pardinas si fuere bibo y a Pedro de Pardinas y a Diego Farina y a Francisco de Pardinas y a Catalina y a Juan y Afonso mis hijos legitimos y de las dichas mis mugeres // al qual doy todo mi poder complido para que puedan entrar en los dichos vienes hazer dellos a su boluntad // y cumplido e pagado heste mi testamento y lo en el contenido mando se cumpla y guarde como en el se contiene // Y rreboco otro qualquiera testamento que antes de agora aya echo y quiero que valga heste como en el se contiene que fue fecho y otorgado en la ciudad de Santiago a a veinte y ocho días del mes de junio de mil e quinientos e nobenta e quatro anos hestando presentes por testigos Alonso Pérez de Araujo e Juan de [Amorin] y Domingos de Biloutas // e Benito de Pardinas e Juan Rodríguez sastre veçino de la dicha çiudad y al otorgante yo escrivano doy fee conosco y lo firmo de su nonbre va testado o dize $=$ Por mis cunplidores. Rodrigo de Pardinas [sin.]. Pasó ante mi Domingo Cavaleiro, escribano [sin.]. Doy fee reçebi dos reales de derechos. 
1594, junio, 28. Cidade de Santiago.

Codicilo de Rodrigo de Pardinas.

AHUS, Protocolos, S-503, f. 162.

En la çiudad de Santiago a los dichos veinte y ocho días del mes de junio de mil y quinientos e noventa e quatro anos Rodrigo de Pardinas por bia de codeçilo mando lo siguiente.

Yten dixo que Pedro Farina [me iço] un ofiçio de primero número de la Real Audiençia e yo soy su fiador del çenço que tomo para hel suplicole que tenga quenta con Diego mi hijo y mire por el y abiendo de disponer del ofiçio se lo de a [hel] por lo que otro le diere.

Yten dixo quel Raçionero mi hermano me debe siete ducados que le presté para una deuda que debía a Juan de Cobas clérigo mando los cobren del.

Yten digo que yo de por fiador del clérigo del ospital de Bulma y San Pedro de Visono y pague beinte y seis ducados por el y que de [...] de Françisco López de Calçada y para hello me dio el dicho secretario [Cierneles] // suplico le de horden si se pueden cobrar clérigo lo demás y ansimesmo le de una obligaçion al mismo Calçada contra [uno] de la [mina] de unos setenta e tantos reales // y para hesto setenta e tantos rreales cobre una partida de Gomez Rodríguez de Moconco para [hesta] partida suplicole aga quenta con mis Herederos.

Yten digo que Francisco de Pardinas mi sobrino me deve quatroçientos e tantos rreales por una firmada suya y para en quenta dello me dio dos canedas de plata doradas y dos pares de almendrillas de concha mando mis herederos agan quenta con el y se cobre el que deviere // y ansí lo otorgo ante mi escrivano y testigos estando presentes por testigos Alonso Pérez, Juan de Amorín y Domingos de [Viloutas] e Benito de Pardinas e Juan Rodríguez sastre [...] y estantes en la dicha çiudad y al otorgante yo escrivano doy fe conosco y lo firmo. Rodrigo de Pardinas [sin.]. Ante mi Domingo Cavaleiro, escribano [sin.] [...]

1605, novembro, 9. Cidade de Santiago

Testamento de Catalina Oanes, muller de Rodrigo de Paradinas, veciña da cidade de Santiago.

AHUS, Protocolos, S-800, ff. 377 - 379. 
Yn dei nomine amen sepan quantos esta carta de manda e testamento ultima e postrimera voluntad vieren como yo Catalina Oanes muger de Rodrigo de Paradinas vezina de la çiudad de Santiago que soi presente estando enferma de enfermedad natural que nuestro senor fue servido de me dar temiendo e rreçelandome de la ora de la muerte que es cosa natural a todo fiel xpiano ago y ordeno mi manda e testamento por la qual encomiendo mi ánima a nuestro senor jesucristo que la conpró e rredemio en el árbol de la santa vera cruz e ruego por merçed a la gloriosa birgen santa maría nuestra senora quiera ser mi abogada para que mi alma merezca entrar a goçar en su santa gloria con sus santos amen.

Yten digo que si nuestro senor fuere servido de me llebar desta presente vida mi cuerpo y carnes pecadoras sean sepultados en la capilla de San Benito del Canpo desta çiudad en la capilla que alli hiçimos yo y mi marido Rodrigo de Pardinas.

Yten mando que my cuerpo al tienpo de mi falesçimiento baya bestido en un avito del senor San Francisco con yntenzión de goçar de las graçias de los que en el se sepultan y se pague por ello la lymosna acostumbrado.

Yten mando se llame para mi entierro y onrras las cofradías que paresçiere a mis cunplidores y se llamen los conventos de San Francisco y San Lorenço y se le pague lo acostumbrado.

Yten mando a la Santa cruzada e rredençion de cautibos un real y con esto la aparto de mis vienes.

Yten mando se digan por my anima el día de my entierro y onrras quarenta misas y se digan a boluntad de mis cunplidores y en la parte donde ellos quisieren y se me digan luego quatro missas en la capilla de las anymas de la Santa Iglesia de senor Santiago y se pague por ello la limosna acostunbrada.

Yten digo que por quanto Catalina Oanes my hija questa por cassar en my casa me a servido asta aora horradamente y por el vuen amor que le tengo y serviçio que me a echo para ayuda de su casamiento le mando el terçio e quinto de mis vienes ansi muebles como raiçes para que ella y sus herederos lo lleben para sienpre jamás y le ruego me perdone, y que rruegue a Dios por my anima y en el dicho terçio e quinto de [mis] vienes la mejoro.

Yten dejo al dicho Rodrigo de Pardinas my marido por usofrutuario de todos mis vienes ansy muebles como rraiçes que entranbos y dos ganamos y adquerimos para que los goze y usufrute durante los días de su vida y despues de su falesçimiento que den a sus herederos y los partan yguales partes tanto uno como otro conforme a este my testamento sacado el dicho terçio e quinto que dejo a la dicha Catalina Oanes mi hija.

Yten dejo por mys cunplidores e testamentarios desta my manda e testamento al dicho Rodrigo de Paradinas my marido y a Bartolomé [Gonçales] clérigo e retor de 
la dicha capilla de San Benyto y a Pedro de Pardinas hijo del dicho my marido y retor de Santo Andrés Dillobre y a cada uno dellos ynsolidum a los quales doi mi poder cunplido para que cunplan my testamento a costa de mis vienes y sin dano de los suyos.

Yten dejo por mis herederos unibersales en todos mis vienes después del falesçimiento del dicho Rodrigo de Pardinas my marido a Diego de Pardinas y frai Francisco de Barrientos y a Catalina Oanes y a Juan de Pardinas y Alonso Farina mis hijos y del dicho Rodrigo de Paradinas my marido para que los ayan y lleben con la bendiçión de Dios y la mía por yguales partes ecepto la dicha Catalina Oanes mi hija que llebe el dicho terçio y quinto de mis vienes de [Montemayor] y después entre con los más mis herederos y llebe la parte que le cupiere.

Y esta dejo ago y otorgo por my manda e testamento última e postrimera boluntad.

Yten demás de lo aquí [otorgado] digo que por quanto yo y el dicho mi marido tenemos un entierro en la capilla de San Benito del Canpo y por que mi boluntad hes que en el dicho entierro aya alguna dotaçion de misas e memoria de misas por mi alma y del dicho mi marido quiero y mando y es my boluntad y doy comisión al dicho my marido para que pueda açer la dicha dotaçion de mysas como le paresçiere y cargadas sobre [nuestros] vienes y mando que como el hordenare ansi se aga y cunpla y que ninguno de mis herederos pase contra ello.

Y Reboco y doy por ninguno e de ningún efeto otros qualesquiera testamentos y codicillos que antes deste aya fecho para que no balgan sino este que al presente ago y otorgo por delante el presente escrivano que quiero que balga por my manda e testamento ultima boluntad e como de derecho mejor aya lugar y ansi los otorgo antel presente escrivano e testigos que fue fecho e otorgado en la ciudad de Santiago a nuebe días del mes de nobienbre de mill e seisçientos e çinco anos estando presentes por testigos Pedro Rodríguez cordonero y Juan de Billanueba y Gregorio Garcia e Juan Gonçales veçino de Santispiritus e Diego Pasqual [mercader] veçinos y estantes en la dicha çiudad e yo escrivano doy fee conozco a la otorgante e a su rruego lo firmaron los dichos testigos y la dicha otorgante a echo, que otorgó este testamento estaba en su juiçio y entendimiento natural por las rraçones que dio y [conoçimiento] de testigos testigos los dichos. Como testigo y a su ruego Pedro Rodríguez [sin.]. Joan de Vilanoba [sin.] Como testigo Diego Pascual [sin.]. Como testigo [el ...] Juan Gonçalez [sin.]. Como testigo Gregorio Garçia Doya [sin.]. Pasó Ante mi Pedro Díaz de Valdevieso, escribano [sin.]. Doy fe no [rrecibe] derechos Valdevieso [sin.]. 


\section{6}

1609, febreiro, 6. Cidade de Santiago.

Auto de apertura de testamento e testamento de Rodrigo de Pardinas, veciño da cidade compostelá.

AHUS, Protocolos, S-811, ff. 368 - 382.

En la çiudad de Santiago a seys días del mes de hebrero de mill y seisçientos e nuebe anos por ante mi escrivano e testigos estando presentes Diego de [Paz] alcalde ordinario de la dicha çiudad y su jurisdiçión paresció presente Diego de Pardinas [procurador] en la audiencia arçobispal vezino de la dicha çiudad y dijo que a su notiçia era benido que $\mathrm{R}^{\mathrm{o}}$ de Pardinas su padre vezino que fue de la dicha çiudad abia echo y otorgado su testamento por delante mi escrivano çerrado y sellado y aora se abia falesçido desta presente vida y para que se supiese donde se mandava sepultar y lo mas que mandaba y legatava el dicho su padre por el dicho su testamento dijo que pedía e pedió a (tach.) mi escribano (tach.) su merçed el dicho alcalde mandose abrir leer y publicar el dicho testamento y a el e sus [traslados] e clausulas (tach.) ynterponia (tach.) ynterpuso[le] su autoridad y decreto judiçial y pedio justiçia y visto por su merçed el dicho alcalde mando que yo escrivano eseviese el dicho testamento el qual luego yo escrivano esevi y por su merced el dicho alcalde visto mando que el dicho Diego de Pardinas diese diese ynformazion de la conprobaçion del dicho testamento y dada proveria justiçia y ansi lo probeyo e mando e firmo de su nombre, testigos Gregorio Garçia e Andrés Fernández e Francisco de Pardinas vezinos de la dicha ziudad. Va emendado o dize siese [...] Va testado o deçia mi escrivano ynterponia e no vala. Diego de Paz [sin.] = Pasó Ante mi Pedro Díaz de Valdibieso, escrivano [sin.]

Juramento de testigos

E despues de lo susodicho en la dicha çiudad de Santiago ano día mes susodichos el dicho Diego de Pardinas para conprovazion del dicho testamento presentó por testigos a Gregorio Garçia, escrivano y a Andrés Fernández, mercader, y a Juan de Parga y a Juan Calbo vezinos de la dicha ciudad de los quales y de cada uno dellos el dicho alcalde Diego de Paz tomó y resçivio juramento en forma sobre una senal de cruz en que pusieron sus manos derechas y prometieron de deçir verdad de lo que supiesen y por que [fuesen] preguntados testigos de les ver jurar los unos de los otros y lo senalo el dicho alcalde. Ante mi Pedro Díaz de Valdebieso, escribano [sin.].

Testigo el dicho Gregorio Garçia escrivano vezino de la dicha ziudad de Santiago susodicho presentado por el dicho Diego de Pardinas para ynformaçion de lo 
contenido en su pedimiento y conprovazion del dicho testamento despues de aver jurado en forma dijo el dicho testigo que conozçio al dicho Rodrigo de Pardinas siendo bibo de entero conozçimiento e que sabe y es verdad y bio que el dicho Rodrigo de Pardinas estando llebantado y con su juizio natural en veinte e nuebe dias del mes de henero pasado deste presente año de mill e seysçientos [e] nuebe estando en esta ziudad por ante el testigo y de Andrés Fernández e de Juan de Parga y otros e por ante mi escrivano otorgó su manda e testamento çerrado y sellado e rreboco otros que antes deste antes ubiese fecho para que no baliesen y lo firmó y lo mismo este testigo y los mas que se allaron presentes de rruego del sobredicho [nel] otorgamiento del dicho testamento al qual el testigo se rrefiere y siendo al dicho testigo mostrado el dicho testamento çerrado y sellado dijo que es el mismo papel que el dicho Rodrigo de Pardinas otorgo en tal su manda e testamento y esta en la forma que el le otorgó y reconoze la firma que en el está que dize soy testigo Gregorio Garçía escrivano ser del testigo y avello echo de ruego del dicho Rodrigo de Pardinas al tienpo que se otorgó el dicho testamento e lo mismo reconoze las más firmas que en el dicho otorgamiento de testamento están en cada una de las [...] que ellas lo declaran por el testigo que testigo ynstrumental del otorgamiento del dicho testamento y les vio azer y escrebir y dize mas el dicho testigo que sabe y es verdad que el dicho Rodrigo de Pardinas se falesçio oy dicho día y se tanen por el las canpanas y esto es la verdad y lo que sabe de lo susodicho en lo qual se afirmo e rratifico y lo firmo de su nonbre e dijo ser de hedad de veinte e siete anos poco más o menos e no le tocan las generales // Gregorio Garçia, escrivano [sin.] Paso Ante mi Pedro Diaz de Valdevieso, escribano [sin.].

Testigo el dicho Andrés Fernández, mercader, veçino de la dicha çiudad de Santiago testigo susodicho presentado por el dicho Diego de Pardinas para conprovaçion del dicho testamento e despues de aber jurado en forma dixo el testigo que conosçio a rr $^{\circ}$ de Pardinas veçino que fue desta ciudad en su bida siendo bibo y que sabe y es verdad y bio quel dicho Rodrigo de Pardinas y estando [lle]bantado y con su juiçio natural en esta ciudad de Santiago en veinte y nuebe del mes de henero deste presente ano por ante el testigo y Gregorio Garçia y de Juan de Parga y otros y por ante mi escrivano otorgó su manda y testamento çerrado y sellado (tach.) yacia se abia falesçido desta presente vida y para que se supiese donde (tach.) y por el auto del otorgamiento del dicho testamento reboco otros qualesquiera testamentos y codeçillos que antes dentonçes ubiese fecho para que no valiesen y lo firmo y lo mesmo el testigo y los mas de rruego del sobredicho en el auto del otorgamiento del dicho testamento al qual el testamento se refiere y siendo al dicho testigo mostrado el dicho testamento çerrado y sellado según por mi [escrivano] fue 
esibido y por el testigo visto y mirado dixo que hes el mesmo papel quel dicho Rodrigo de Pardinas otorgó por tal su testamento y está en la forma que el lo otorgó y rreconosçe la firma que en el hesta que dize como testigo Andrés Fernández hes del testigo y [abella] echo al tiempo que se otorgó el dicho testamento de rruego del dicho Rodrigo de Pardinas y lo mismo rreconoce las mas firmas que en el están ser cada una de las personas que [ellas] lo declaran porquel testigo fue testigo ynstrumental del otorgamiento del dicho testamento y las bio açer como dicho tiene y dize mas el dicho testigo que sabe y es verdad quel dicho Rodrigo de Pardinas se falescio desta presente bida oy dicho día y esta amortaxado y para sepultar y esta es la verdad y lo que sabe de lo suso dicho en lo qual se afirmo e retifico y lo firmó de su nombre y dixo ser de hedad de quarenta anos poco más o menos y no le tocan las generales y lo senalo el dicho alcalde. Va testado do diçia y aora se abia falescido desta presente vida y para que se supiese donde no vala. Andrés Fernández [sin.]. Ante mi Pedro Diz de Valdevieso, escribano [sin.].

[...] testigo el dicho Juan de Parga residente en la dicha ziudad testigo susodicho presentado por el dicho Diego de Pardinas para conprovación del dicho testamento e despues de [haver] jurado [e firmadolo el testigo] que conoscio a Rodrigo de Pardinas veçino que fue desta ciudad siendo bibo de entero conocimiento y que sabe y

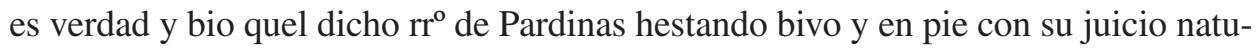
ral en veinte y nuebe días del mes de henero deste dicho ano otorgó su manda y testamento en escrito çerrado y sellado por ante el testigo y de Andrés Fernández y de Gregorio Garzía y otros y por el auto de otorgamiento del reboco otros que ubiese fecho antes dentonçes para que no valiesen sino el que ansí hacía y el testigo con los más lo firmo en el auto de otorgamiento del dicho su [testamento] al qual se refiere y siendo al dicho testigo mostrado el dicho testamento cerrado y sellado según que por mi escrivano fue esibido por el testigo visto e mirado dixo que hera el mesmo papel quel dicho Rodrigo de Pardinas otorgó por tal su testamento y que esta es la forma y manera que el lo otorgó por quel testigo fue uno de los testigos ynstrumentales del dicho testamento y bio hazer las firmas que en el están y lo mesmo la ques del testigo y por tal las rreconoce y dize más el testigo que sabe y es berdad quel dicho Rodrigo de Pardinas se falescio oy dicho día desta presente vida y esta amortaxado y para sepultar y se tanen por el las canpanas y esta hes la verdad y lo que sabe de lo susodicho en lo qual se afirmo e ratifico y lo firmó de su nombre y dixo ser de hedad de veinte y quatro anos poco mas o menos tiempo y que no le tocan las generales de la ley por que fue preguntado y lo [senalo] el dicho alcalde $=$ Jhoan de Parga [sin.] = Ante mi Pedro Diaz de Valdevieso, escribano [sin.] .

Testigo el dicho Juan Calvo Residiente en la dicha ziudad de Santiago testigo susodicho preguntado por el dicho Diego de Pardinas para conprovaçion del dicho 
testamento e despues de aber jurado en forma dixo el testigo que conosçio a Rodrigo de Pardinas vecino que fue desta çiudad siendo bibo de entero conosçimiento y que sabe y es verdad y bio quel dicho Rodrigo de Pardinas hestando bivo y en pie con su juicio natural en veinte y nuebe días del mes de henero deste dicho ano otorgó su manda e testamento en escrito çerrado y sellado por ante el testigo y de Gregorio Garzía y de Andrés Fernández y otros y por el auto de otorgamiento del rreboco otros que ubiese fecho antes de entonçes para que no valiesen sino el que ansí facía y el testigo con los mas lo firmó en el auto de otorgamiento del dicho testamento al qual se rrefiere y siendo al dicho testigo mostrado el dicho testamento çerrado y sellado según que por mi hescrivano fue exsibido y por el testigo visto y mirado dixo que hes el mesmo papel quel dicho Rodrigo de Pardinas otorgó por su testamento y que hesta en la forma y manera que el lo otorgo por quel testigo fue uno de los testigos ynstrumentales del dicho testamento y bio haçer las firmas que en el hestan y lo mesmo la ques del testigo y por tal las reconoze y dize más el testigo que sabe y es verdad quel dicho Rodrigo de Pardinas se fallescio y dicho dia de esta presente vida y esta amortaxado y para sepultar y se tanen por el las canpanas y esta es la verdad y lo que sabe en lo qual se afirmo e rrubrico y lo firmo de su nombre y dixo ser de hedad de diez e seys anos y no le tocan las generales de la ley por que fue preguntado y lo senalo el dicho alcalde. Juan Calbo [sin.] = Pasó Ante mi Pedro Díaz de Valdevieso, escribano [sin.].

Auto. Vista esta ynformaçion Por el dicho Diego de [Paz] justiçia y alcalde ordinario de la dicha ciudad de Santiago y su jurisdición dixo que mandava y mando abrirlas y publicar el dicho testamento que pareze otorgó el dicho Rodrigo de Pardinas y a el y sus traslados y clausulas ynterponía ynterpuso su autoridad y decreto judiçial tanto quanto podía y abía lugar de derecho para que valga y ago fee en Juiçio y fuera del y mando a [mis...] del dicho testamento y sus clausulas de los treslados nesçesarios a las partes que los pidieren y a quien [paresçieren] signados por mis derechos y ansi lo [proveyo] mando y firmo de su nonbre en la ciudad de Santiago a [seis] días del mes de hebrero de myll y seiscientos e nuebe anos. Diego de Paz [sin.] = Pasó Ante mi Pedro Díaz de Valdivieso, escrivano [sin.] Debeseme los derechos. Valdevieso [sin.]

1609, xaneiro, 29.

Testamento de Rodrigo de Paradinas.

Yn Dei nomine amen sepan quantos la presente escritura de testamento ultima y postrimera boluntad vieren como yo Rodrigo de Paradinas veçino que soi de la çiudad de Santiago yndino estando sano y en mi xuiçio y entendimiento natural tal 
qual mi señor dios fue serbido darme pero por que la muerte es la cosa más çierta que los onbres tenemos y por deuda natural y por ella emos todos de pasar pero porquel día y la ora ora [sic] a la qual emos de ser llamados en xuiçio delante nuestro señor Dios ninguno lo sabe ni lo puede alcançar por lo qual nos conbiene sienpre estar belando y mui aperçebidos para que quando nuestro señor xesucristo fuere serbido llamarnos a quien umilmente [sic] suplico sea serbido alunbrar mi anima y entendimiento y me de su fabor y graçia para que ansi en el ordenar deste mi testamento como en lo demas tocante a su serbiçio açierte [...] mi anima y haçienda en tal manera que por ella su dibina maxestad sea serbido y los proximos acariçiados y mi anima y haçienda libre de la bision y podería del demonio y en el transito de mi bida a la muerte atento lo qual y teniendo como tengo todo mi entendimiento y juiçio digo y confieso ly creo/ la santisima trinidad padre, hixo y espiritu santo tres personas y un solo Dios berdadero en quien creo y adoro confieso y cre todo aquello que la Santa yglesia romana tiene y cre y confiesa confiesa [sic] la santisima virxinidad de la santisima birxen sin mançilla nuestra señora y abogada a quien umilmente [sic] suplico tenga por bien de suplicar a su hixo bendito por mi y a la ora de mi falleçimiento sea mi protetora y defensora para que su bendito hixo no entre conmigo en estrecho juiçio y que perdone mis culpas y pecados y me libre del poderío y dibisión del demonio y de la condenaçion eterna y sea serbido darme la gloria para que me crio y ansi xuntamente mencomiento al glorioso apostol señor Santiago mi patrón con todo el colesio de los apostoles y al bendito San Lorenço con la conpania de los martires y al señor don Frutuoso con toda la multitud de los confesores y a señora Santa Catalina con todas las birxines a señora Santa Ana con todas las [continientes o] señor San Migel y San Grabiel con todos los coros de los anxeles sean serbidos suplicar a Dios nuestro señor por mi anima pecadora y a la ora de la muerte sean guarda y anparo della para que no sea [apresa] ni escarnida del poderío del demonio y ansi tiniendo confiança en la infinita misiricordia divina y que como my señor y criador y redentor myrara por su criatura por quien su preçiosísima sangre derramo ordeno este mi testamento y ultima boluntad en la manera sigiente.

Primeramente mando mi anima a mi señor xesucristo que la conpró y redimió por su preçiosísima sangre.

Yten mando que quando mi señor xesucristo fuere serbido de me llebar desta presente bida mi cuerpo sea sepultado en un abito de señor San Francisco y pagen por el de mis bienes lo acostumbrado.

Yten mando que mi cuerpo sea sea (sic) sepultado en la capilla de señor San Benito del Canpo en esta çiudad de Santiago en el entierro que allí tengo hecho a mi costa en el altar coliteral a la parte ysquierda en el lado del ebanxelio la qual hiçe 
a mi costa y la tengo dotada en quatro reales perpetuos y digo que si me muriere fuera de la çiudad de Santiago y [...] lugar [ni] abiendo enpedimiento a costa de mis bienes me traigan a la dicha capilla a enterar.

Yten mando llamen para mi entierro y onrras la confraria de Nuestra Señora del Rosario al qual suplico al qual suplico (sic) al mayordomo y confrades siendo serbidos mentierren ellos atento que a mas de quarenta años que sienpre e serbido en la dicha confraria en ocasion que me an mandado y encargado ansi mayordomo como bicarios y confrades della y para ayuda de çera que se gastare les mando seis ducados y les suplico me onrren por serbiçio de Dios.

Y ansi mismo mando llamen a las confrarías de que soi confrade que son la confraria de la bera cruz y la confraria de nuestra señora de la antigua de los mercaderes y la de señor Santiesteban y de Señor San Tome y de señor [San Xia] de que todas ellas soi confrade / y a todas les pagen lo acostunbrado / y se se debieren algunas caridades se pagen de mis bienes.

Yten mando a la Santa Cruçada y rredençion de catibos un rreal con el qual los aparto de todos mis bienes.

Yten mando al clérigo que me ayudare a bien morir quatro rreales por su trabaXo.

Yten mando el día de mi entierro y onrras y cabo de año me digan por mi anima cinquenta misas rreçadas y diez cantadas y dos misas en la capilla de las ánimas.

Yten mando lleben de ofrenda a la ylesia [sic] con mi cuerpo un quarto de carne y dos rreales de pan coçido y un açunbre de bino y dos hachas de çera ençendidas.

Yten mando el día de mi entierro y onrras den de limosna a pobres dos ducados.

Yten mando den quatro ducados a quatro pobres bergonçosos a cada uno un ducado a vista de mis cunplidores.

Yten digo que Gutierre de Bia que bibe en Altamira me debe çinto y quarenta rreales de rresto de una parte del benefiço de Santa María de Los Anxeles que le arrende y me los quedo a deber mando los cobren del.

[á marxe: censso] Yten digo que yo tengo un çenso de Balbis que les pago quinçe ducados y otro de capillas que le pago ocho ducados que ya quedó de Pero Barela mi suegro y otros çiento y veinte y nueve del [colesio] de Santispritus que saque para pagar un deposito de unos naipes / y cien ducados que debo a Mateo do Couto mando a mis cunplidores y erederos que ante que partan ni que dibidan mis bienes lo rrediman y bendan mis bienes para los rredemir los que menos daño rreciban.

Yten digo que yo tengo un pleito en la Coruña pasa en el ofiçio del secretario figeroa contra los bienes de Ana Dortega sobre çien ducados que me debia del dote de Catalina Oanes mi muxer y sobrello una sentençia antel asistente en el ofiçio de 
Figeroa questa en un pleito de acredores que pidio el canonigo Eliseo a los dichos bienes y allí una sentençia en mi fabor y se bendieron algunos bienes que avia y está depositado el dinero en poder de Diego de Pol mercader y ocho toneles en poder de Bernal Madera aunque [sic] poder de $\mathrm{R}^{\mathrm{o}}$ de Figeroa quedaron tres dellos que los prestó a Diego de la Rúa y doçe ducados que el dicho $\mathrm{R}^{\circ}$ de Figero abia de dar del alquiler dellos por un año toda la raçon esta en el pleito questa en su poder mando mis erederos hagan ber.

Yten digo que a mi me deben muchos marabedis ansi por memorias questan en mis libros y papeles y obligaçiones y conoçimientos digo que todo lo questubiere por borrar se me debe liquido y digo que si alguno en algo rrepare que sea poca cosa siendo onbre onrrado sea creido por su xuramento digo que por la cuenta que tengo de dar a mi Dios que todo se me debe lo questubiere por borrar ansi en obligaçiones y memorias.

Yten digo que Juan Paxaro [en foxa...] tenemos una cuenta de un año que le arende a el y a Ortigeira los bot[e]s de baba y dellos me debe ciertos marabedis que son mas de doçientos reales por la cuenta questa en mi poder mando mis erederos los cobren del y si repararen en las cuentas las tornen a ber por que lo coxeron el y Ortigera para si y para mi en treinta y seis marabedis yo los page / y tanbien coxera otro año y Juan Paxaro del me mando pagar ocho hanegas de pan que son de otra cuenta.

$\mathrm{Y}$ ansi mismo me debe Ortigeira quatro ducados que le preste para para [sic] haçer una çinta y mas un marco de almendrillas doradas que lenpresté diome parte dellas esta en mi libro las que son.

Yten digo digo [sic] que Juan Costal en el puesto Bendaña me debe hechas cuentas con el y con sus hixos hasta el año de 98 [sic] çiento y setenta y dos reales conforme a la cuenta questa en mi libro / y mas me tiene en su casa una arca de quatro pies mando lo cobren del ques ya tienpo.

Yten digo que quando me case con María Fernández mi segunda muxer, madre de Pedro de Pardinas mi hixo hiçe recuento de mis bienes questa en mi poder y conforme a el se an de giar mis erederos y ansi los tenía quando me case con Catalina Oanes mi postrera muxer y esto declaro para que mis erederos no tengan diferençias //

Yten digo que María Fernández mi segunda muger y madre de Pedro de Pardinas mi hixo por muerte de Pedro Barela y de María Fernández, sus padres y madre truxo a mi poder yo uve con ella que eredo de sus padres los bienes raiçes questan en la partixa que hiçimo yo y Pedro Barela mi cuñado que pasó una delante Pedro Rodrigues escribano y otra que refie [sic] aquella que paso ante Negreiros escribano del numero que al tienpo era a las quales me refiero mando que mi hixo Pedro 
de Pardiñas llebe todo lo que le cabe como bienes que quedaron de su madre y aguelos y despues entre en partixa con los mas mis hixos en los bienes que mas sobraren cunplido mi testamento //

Yten digo que con la dicha María Fernández uve algunos haxuares que me cupieron y eran pocos mando que por ellos le den al dicho Pedro de Pardinas una cama de ropa aparte conplida con dos almohadas que fueron de su madre labradas y unos manteles largos alimanisco con quatro serbilletas de lo mismo que tanbien fueron della y unas [façelexas] labradas y una ucha y una mesa de gonçes / y una taça de [bestianes] antigua que todo de su lixitima / y despues entre a partir con los demás con la bendiçion de Dios y la mia y lencargo mire por su hermana y los mas questan por remediar //

Yten digo digo [sic] que yo reçebi con Catalina Oanes mi muxer quatroçientos ducados en dinero y ansimismo los çiento questan por cobrar del pleito con Ana Dortega de que tengo sentençia en mi fabor.

Yten digo que yo merqués a los hixos de Juan Abad en Galegos el lugar de Galegos donde lo poseo y me costó mucho y en el tengo hechos muchos perfetos y ansimismo estaba bendido sobrel y enpeñado mas de ocho cargas de çenteno yo e redemido y recobrado mucha parte del y aun se debe a la teneçia de Anibal Rodrigez de los dos terçios de la labra[va] de Liñariños y de la leira de [Liçeiras] lo que baliere de renta aunque yo hasta aora pagaba dos cargas y no lo baliendo mis erederos se lo dexen y lo arrienden a quien mas le diere al teneçiero ques o fuere // y ansimismo pagan a Rodrigo da Fonte tres fanegas de çenteno aunque yo estoi me diron puesto con el y mas pago una carga a Domingos de Losada estas son [sisas] y no tienen buenos recaudos digo que si se pudieren dando sus dineros redemir se rediman porque no dieron sin a veinte y quatro ducados por la carga del çenteno baliendo como bale a quarenta ducados / y tambien tenía bendido a Pedro Abraldes otra carga sobre el dicho lugar y dexe otra en reconpensa que merque en su lugar que fue de Afonso Pérez.

Yten digo que yo tengo en Santo Adrao de Bieite en el Ribero Dabia çiertos bienes que son treinta y seis cabaduras de biña y un lagar de piedra y una torre todo debaxo de un techo y otra bodega y ocho cubos que llebaran çiento y treinta moyos bien aforados de los quales bienes están los papeles en mi poder y los mas están en poder de Gonçalo Rodriges en San Clodio y a mi me daban por ellos quinientos ducados mando mis erederos los bendan si no los pudieren granxear u los den a mi hixa Catalina Oanes en casamiento con los mas bienes que les pareçiere.

Yten digo que a mi me deve algunos dineros en la dicha felegresía de Santo Adrao por memoria y obligaçiones digo que se rixan por el memorial y por las obligaçiones y me remito al libro y no a las obligaçiones. 
Yten digo que yo y Pedro Mallo tenemos [cantidad] deguas que son mias y suyas de por medio y un burro lo mismo las quel dixere quel dira la berdad y se haga cuenta con el [en] su tienpo y se xiran por mi libro las cuentas que tengo con el dinero que le tengo dado para mercar o aseñalar algunas mulas para entranbos para xuntarlas con las que naçieren de las muestras quel dira la berdad de lo que asy todo lo quel dixere sea creido.

Yten digo que Françisco Lopez de Calçada secretario del Santo Ofiçio me rogó quedase por fiador de Domingos Pérez retor que fue de San Lorenço de [Bruma] sin ya lo conoçer porquel le tenía arrendado el benefiçio y por el me esecutaron yo page por la dicha fiança veinte y seis ducados mando los pidan a sus erederos para su muxer sabe la berdad y ansimismo me cobro el dicho secretario de Domingos Lopez veçino de San Pedro de Bisoño setenta reales de lena obligaçion que me los cobrase y el los cobró en dos yeguas que le dió en pago dellos y digo que de todo ello no cobre mas de çien reales mando que mis erederos los cobren que María de Pardiñas su muxer Sabe la berdade todo esto que digo y esta es la verdad.

Yten digo que yo merque a Domingo Abad y a su hixo Afonso Abad leira de [Soutullo] en [treinta] ducados digo la leira de Chaos y me abian de dar de renta tres $r a$ (sic) rapadas de pan de renta della en seis anos que la labro Afonso Abad y no me dio mas de una carga de pan mando cobren lo mas.

Yten digo quel bachiller Suarez de la Fuente de la [Unlla] me llevo un tonel de la casa de Rodrigo de Fonte que yo abia enprestado a Rodrigo da Fonte mando lo cobren que Juan da Fonte carpintero sabe qual es que lo hiço

Yten mando a la lunbre [...] sacramento de señor San Benito una [quart... y da] daçeite asemade y otro a nuestra señora la Preñada entrusa en la ilesia de señor Santiago por una vez.

Yten mando me digan un treintanario que son treinta misas por mi anima y de quien soi obligado en el monesterio de senor San Lorenço y le pagen de limosna lo que se paga por una [vez].

Yten digo que [Fernando] de Pardiñas mi sobrino me debe una cadena dorada en treinta y seis reales / y mas me debe por Juan Calvo de Çime [...] reales y quarenta y un reales del alcançe de la sincura de Bila do Abad mando los cobren del.

Yten digo que dexo y mando a mi hixa Catalina Oanes el terçio y quinto de mis bienes de la parte que me toca y como mexor uviere lugar y en lo mexor parado dellos y esto se lo mando mas y aliende de lo que le mando su madre y por ser muger para remedio y ayuda de su casamiento y por buenos serbiçios que me a hecho / y en los bienes remaneçientes cunplido este mi testamento y legatos del dexo y nonbro por mis ereros [sic] en los mas bienes que [...] de Santo Andrés de Illobre y a Diego de Pardinas procurador de causas en la audiençia arçobispal de 
Santia [sic] y a Frai [Francisco] de Barrientos, monxe de Celanoba y suplico al padre abad y conbento del dicho monesterio [bea] que mis bienes son pocos y están mui cargados y nos haga caridad para ayudar de casar mi hixa de la parte que tocare y a Catalina Oanes mi hixa y Alonso Fariña todos mis hixos / y digo que a Juan de Pardiñas mi hixo en lo que puedo y ai derecho lo deseredo de la parte que le tocare de mis bienes por causas que a [esto] me mueben y por me aver sido mui desobidiente y hecho cosas de enemigo en lo de la parte de su madre se le puede dar / y a los mas lo lleven con la bendiçión de Dios y con la mía y les encargo ruegen a Dios por mi anima.

Yten digo quen mi poder en una ucha esta una colcha buena que no es mia sino de mi hixa Catalina Oanes que se la dio el Raçionero mi ermano para su casamiento // mando la aya y llebe $=$

Yten mando se me digan por mi anima y de quien soy obligado en cada un ano para sienpre jamas quatro misas rreçadas en la capilla de San Benito del Canpo a donde tengo echo mi entierro y gaste en el más de setenta ducados [...] dichas mysas mando las digan en cada un ano para [...] la dicha Catalina Oanes [...] y sus herederos y deçendientes las quales se digan dos días antes de senor San Juan o dos días despues de cada un año y pague la limosna de las dichas misas según se conzertare con los clérigos que se las dixeren y para ellas dejo a la dicha mi hija y sus herederos las dos terçias partes de la casa que tento en la entrada de la rrua nueba que conpre a Juan Fernandes de Santiago en que bive [María] López biuda de que me paga en cada un ano siete ducados los cuales [dichas] dos terçias partes de casa según [...] que entran en la parte que cave a la dicha mi hija del terçio y quinto de los mis vienes [que] le mando [...] a de pagar en cada un ano la dicha my hija sus herederos quatro rreales que pago a la lunbre del Santisimo Sacramento de senor San Venyto por el sitio que alli me dieron los feligreses de la dicha capilla para mi entierro y todo lo susodicho y misas a de pagar la dicha my hija y sus herederos de las dichas dos terçias partes de casa que ansi le mando y le rruego y encargo que en esto aya cuidado en que se cunpla esta clausola y ruegue a Dios por my anima por que esta hes ansy mi boluntad.

Yten digo y declaro que Diego de Pardinas my hijo tiene rresçibido de mi para en quenta de su legitima dos mill y tantos rreales de que [le] ago carta de pago y memorias mando y es mi boluntad que la mitad de los dichos [maravedís] el dicho Diego de Pardinas los aya e tome en quenta de su legitima y la otra mitad se los quito e perdono para ayuda de criar a sus hijos y porque rruegue a Dios por my anima.

Yten digo que todo el ganado bacuno se benda para que se cunpla mi testamento y se paguen las deudas que yo deviere y esto se aga y no se vendan vienes rraizes. 
Yten digo y declaro que de mi muger María Fernándes madre de Pedro de Pardinas clérigo, mi hijo me quedó una hija hermana del dicho mi hijo la qual se murio digo e declaro que en razón de la herençia della mis herederos tomen [el] pareszer de dos letrados por quitarse de pleitos y lo que ellos dixeren se [...] herençia de la dicha my hija perteneze al dicho Pedro de Pardinas o a mi como su padre la lleve y si los dichos letrados declararen perteneszerme mando que todos mys herederos la partan hermanamente y esto les encargo por mi vendiçion y que entre ellos non aya pleitos ny lo tengan con la dicha Catalina Oanes mi hija antes la rremedien y anparen como hijos de vendición $=$

Yten dejo e nonbro por mis cunplidores e testamentarios desta mi manda e testamento a Pedro de Pardinas clérigo e retor de Santo Andrés Dyllobre y a Diego de Paz, alcalde ordinario que al presente hes desta dicha çiudad de Santiago y a Diego de Pardinas procurador my hijo y a Jerónimo de Hermosilla, mercader, vezino desta dicha çiudad y a cada uno de dellos insolidum para que cunplan este mi testamento, mandas y legatos en el contenidos aunque sea pasado el ano y día que para ello les doi poder cunplido en forma según se rrequiere.

Yte (sic) dejo ago y otorgo por mi manda e testamento última e postrimera voluntad en la forma que ba dicho y lo firmo de mi nonbre en la ziudad de Santiago a veinte e nuebe días del mes de henero de mil e seisçientos e nuebe anos testigos Gregorio Garçia escrivano que firmó juntamente comigo. Rodrigo de Paradinas [sin.] Como testigo Gregorio Garçia, escribano [sin.].

Y demás de lo arriva rreferido yo el dicho Rodrigo de Pardinas digo que por quanto por una clausolas deste testamento desheredaba a Juan de Pardinas mi hijo y de la dicha mi muger digo que sin enbargo de lo susodicho quiero y es my boluntad quel dicho Juan de Pardiñas mi hijo sea uno de mys herederos y erede mis vienes como uno de los mas y ansi lo digo e declaro y lo firmo de mi nonbre. Rodrigo de Paradinas [sin.]

En la ziudad de Santiago a veinte e nuebe días del mes de henero de mill y seisçientos y nuebe anos Rodrigo de Paradinas, mercader, vezino de la dicha ciudad entrego a mi escrivano este papel cerrado e sellado que dixo hera su manda y testamento y ultima voluntad y por tal manda e testamento lo otorgava y otorgó zerrado y sellado y quería no se abriese asta despues de sus días y rrebocava y rreboco otros qualesquiera testamentos y codeçillos que antes deste ubiese fecho ansi por escrito como de palabra para que no balgan sino [este] que al presente aze y [otorga] çerrado y sellado ante [el pre]sente escrivano e testigos que quería que baliese por tal manda e testigos que quería que baliese por tal manda e testamento y ultima boluntad o en la mejor forma que de derecho ubiese lugar y ansi lo otorgo e firmo de su nonbre estando presentes por testigos Gregorio Garçia escrivano e 
Pedro Rodrigues cordonero e Andrés Fernándes [mercader] e Juan Calbo e Juan de Parga e Graviel descobar e Juan López cordoneros vezinos de la dicha çiudad e yo escrivano doy fee conozco al dicho otorgante el qual al tiempo que otorgo este dicho testamento estaba en su juiçio y entendimiento natural y en pie por las rraçones que dio el mismo [de testigos] y a su rruego lo firmaron los dichos testigos y por los que no supieren unos por otros = Rodrigos de Paradinas [sin.]. Soy testigo Gregorio Garçia, escribano [sin.]. Como testigo Andrés Fernández [sin.] Como testigo Pedro Rodríguez [sin.]. Soy testigo Juan de Parga [sin.]. Como testigo Juan López [sin.]. Como testigo Grabiel Descobar [sin.]. Como testigo Juan Calbo [sin.]

Pasó y se otorgó este auto de otorgamiento de testamento por delante mi Pedro Diaz de Baldevieso escrivano del Rey nuestro [senor] e del número de la çiudad de Santiago y Cavildo conpostelano y en fe dello lo sino e firmo sin derechos. En testimonio de verdad Pedro Díaz de Valdevieso, escribano [sin.] 